\title{
Review \\ Bench-to-bedside review: Leadership and conflict management in the intensive care unit
}

\author{
Rob JM Strack van Schijndel ${ }^{1}$ and Hilmar Burchardi ${ }^{2}$
}

\author{
1'Department of Intensive Care, VU University Medical Centre, PO Box 7057, 1007 MB Amsterdam, The Netherlands \\ ${ }^{2}$ Kiefernweg 2, D-37120 Bovenden, Germany
}

Corresponding author: Rob JM Strack van Schijndel, rob.strack@vumc.nl

Published: 20 November 2007

This article is online at http://ccforum.com/content/11/6/234

(c) 2007 BioMed Central Ltd

\begin{abstract}
In the management of critical care units, leadership and conflict management are vital areas for the successful performance of the unit. In this article a practical approach to define competencies for leadership and principles and practices of conflict management are offered. This article is, by lack of relevant intensive care unit (ICU) literature, not evidence based, but it is the result of personal experience and a study of literature on leadership as well on conflicts and negotiations in non-medical areas. From this, information was selected that was recognisable to the authors and, thus, also seems to be useful knowledge for medical doctors in the ICU environment.
\end{abstract}

\section{Introduction}

Practical management aspects of intensive care medicine do not receive much attention in the critical care literature. There is little evidence-based literature to guide us through management principles. Much of what we know comes from personal experience, courses and literature published by experts in industry or the trades. As intensive care units (ICUs) are facilities where substantial parts of hospital budgets are consumed and where large quantities of human resources are allocated, good management is vital for a successful, adequate and appropriate use of money and people. So, management aspects cannot be overlooked.

In this article for postgraduate physicians, we focus on two aspects of management: leadership and conflict handling from the leader's perspective. Furthermore, as nursing management is crucial for a well functioning ICU, the relationship between physicians and nursing staff is also considered. Where "he" is used in the text, the referred person can of course also be female.

\section{The ICU manager}

The ICU is a place where a multi-professional team works together to care for critically ill patients. Critical care professionals, physicians, nurses and others entirely involved in intensive care form an integrated team who, together with experts from various other specialties, apply their knowledge to provide coordinated patient care. To coordinate so many health care providers and to ensure rapid and effective treatment of critically ill patients is a complex managerial assignment. A long list of key tasks demonstrates the diversity of the commission of an ICU manager (Table 1). However, they can principally be simplified to some general leadership qualities [1], which will be described below.

\section{Leadership}

According to Hersey and Blanchard [2], there are two types of situational leadership, task behaviour and relationship behaviour. Task behaviour means that the leader is oriented towards the necessary tasks. He organises and defines the roles of the group and explains what activities are to be undertaken. For this, well-defined procedures (standard operating procedures) must be developed. Relationship behaviour means that the leader focuses on a good relationship with his team. He maintains the personal relationship between him and the group by communicating and listening, by providing emotional support, and by offering facilitating and supporting behaviour.

Apparently there is no one best form of leadership. Leaders have to match their style to their own requirements and the context of the situation, called 'situational leadership' [3]. This even means that leaders may have to use different styles with different coworkers.

\section{Delegating leadership}

As the team becomes competent and 'mature', the leader can switch over to a delegating leadership. Delegation always motivates the team, creates self-confidence and stimulates the individual team members. People who are

$\mathrm{BOS}=$ burnout syndrome; $\mathrm{ICU}=$ intensive care unit. 
Table 1

Key tasks in intensive care unit management

Directing (leadership, internal/external)

Quality management: quality assessment, continuous quality improvement, error handling, Morbidity and Mortality conferences, risk management, benchmarking, epidemiology and infection control, technology assessment

Knowledge management: training and education (physicians and nurses), life-long-learning, participation at professional meetings and courses

Effective communication: availability of communication technology, communication training, practise of open discussion, communication with non-ICU partners

Research: research financing and resource provision, scientific discussion, scientific experiments and clinical studies, report of planning and results

Medical ethics: patients' and families' advocate, teaching and discussion with ICU staff, promotion of ethical awareness and behaviour, ethics committee, co-operation with social services

'Liason officer': patient and families, physician and nursing staff, hospital administration, department directors and medical partners, regional and professional authorities, and so on

'Policy maker': ICU services, intra-hospital co-operation, healthcare policy, medical professional policy

$\begin{array}{ll}\text { Staffing } & \begin{array}{l}\text { Personnel resources, staff education and promotion, staff psychology and motivation, 'corporate } \\ \text { identity', conflict management, staff advocate }\end{array} \\ \text { Planning } & \begin{array}{l}\text { Change and innovation management, intra-hospital cooperation and concepts, architectural } \\ \text { structure and ICU design, technology acquisition }\end{array} \\ \text { Organizing } & \begin{array}{l}\text { Process assessment and improvement, negotiation with partners, improvement of intra-hospital } \\ \text { processes } \\ \text { Budgeting }\end{array} \\ \text { Budget planning, resource allocation and utilisation, cost containment, cost/effectiveness } \\ \text { assessment } \\ \text { Controlling } & \begin{array}{l}\text { Control of processes, time and resource use, of ICU staff atmosphere, of co-operation with non- } \\ \text { ICU partners }\end{array} \\ \text { Visions } & \begin{array}{l}\text { Improvement of structural conditions and human and physical resources, intra- and extra-hospital } \\ \text { partners and relationships ('network') }\end{array}\end{array}$

competent at performing tasks because of their knowledge and skills are generally highly committed to achieving these tasks and are willing to take on responsibilities. To control the delegated activities, a monitoring system must be established so that the leader is constantly aware of what is happening. Delegation does not reduce or weaken the official, final responsibility of the ICU director. Sudden events can often force the leader to rapidly switch from delegation to task responsibility. Such situations (for example, emergencies) should be defined so that the team knows the rules and respects the leader's intention to be truly responsible. At the least, in any dramatic, emergency situation, it is obligatory that the leader is present ('the captain is on the bridge'). This considerably strengthens team building and respect for the leader.

\section{Personal qualities}

The leader has two faces, one for outside and one for inside. In other words, there are qualities of external leadership and of internal leadership.

\section{External leadership}

Intensive care medicine is a specialty that is highly interactive and interdisciplinary. The position of the director of the ICU should ideally be based on the respect and confidence of the other specialties and their consultants. He should be well accepted by the other directors as well as the hospital administration. It certainly also helps if he has a good reputation within his national society.

With regards to intra-hospital policy and power-play, it is important that the ICU director always tries to go for a 'win/win situation'; otherwise he should say "NO" [4]. On one hand, this builds up a real cooperation from which both partners benefit, which minimises the disadvantages on both sides; on the other hand, it makes clear that there will be no submission to unacceptable conditions. An ICU director's professional partners will come to respect his wish for partnership, but also his clear-cut decisiveness.

An ICU is situated within a complex hospital service network. This necessitates effective and sensitive cooperation with the 
various services. It is the responsibility of the ICU manager to instill in the ICU staff a special sensitivity for these multidisciplinary interactions.

\section{Internal leadership}

As the head of the ICU ('the boss'), the ICU manager is responsible for the atmosphere in the team and its 'mental state' $[5,6]$. Human skills ('emotional intelligence') are the ability to work well with others, which is so important for management work [7]. It is remarkable how much the leader's character determines the 'psychology' of the team. Steven R Covey in his wonderful book The Seven Habits of Highly Effective People [4] recommends: "Seek first to understand, then to be understood." We can only understand if we are listening. If we do not listen, we are obviously not interested in understanding. We can learn much more by listening than by talking. An 'open ear and mind' is needed to understand individual team members, but the leader must remain neutral and objective, since he is the leader of the whole staff and also responsible to the cooperating specialists and the hospital altogether.

\section{Social competence}

Intensive care is teamwork (team = 'family'), but a 'family' needs a head of the family. The basis for this is confidence, not power. The leader does not need to know everything, but he should have an "emotional bank account", as Covey calls it [4]. This promotes an emotional understanding between the coworkers and himself. They then will trust him and he will be well understood, even if the actual situation is going to become a bit difficult.

Individuals' motivation at work is essentially determined by their needs. The less a need is satisfied, the more important it becomes for them [3]. So we must seek to understand what needs they have. Individual needs can be working conditions, job security, compatible working groups, self-esteem, challenging job, and so on. It certainly helps that medical care by itself is extremely motivating, meaningful, charitable and responsible. However, what about the working conditions, the job security? So, social competence also means: not only talk about tasks, also ask about their needs.

One of the most challenging issues for managers is to accept the diversity and the individual differences of their coworkers [3]. Individual differences and contradictions can be annoying and uncomfortable, they can even give rise to conflicts. However, individual diversity can also stimulate creativity, create better decision-making, and cause greater commitment. So, good leaders will be inclined to use such potential, to accept the individual diversity of their coworkers and try to utilise it positively in relation to the team, in disputes and discussions, in planning and organisation, in performance of tasks [8].

Coworkers who feel that their individual personalities are respected by the management will be better motivated. Thus, the leader must foster a climate for tolerating and accepting individual diversity within the team. This exactly characterizes a well-balanced team and it is the best protection against mobbing. A well motivated team has a corporate identity; its members say 'we' because they are proud to belong to the group. The leader is wise to stimulate and intensify such feelings. Nevertheless, the leader must maintain balance and keep the ICU service in a mediating position; 'we are part of the entire hospital's patient care service'.

These are many responsibilities that have nothing to do with medicine. It is obvious that a director must offer many more qualities than 'only' being a good physician. This must be taken into account when looking for an ICU director.

\section{Communication}

Poor communication is the most frequent and critical problem, both within the group as well as between the leader and the group. Poor communication often leads to errors and creates conflicts. Conflicts can only be resolved by communication. Therefore, the skill of interpersonal communication is one of the most important individual qualities of a leader [1].

Communication can indeed be very challenging in the ICU environment, with people working under high stress and work load. This may require specialized tools to ensure clear and concise communication $[9,10]$ : active listening, positive voice tone, reiteration to confirm understanding (who? what? how?) and written summaries reflecting the content of a discussion (for example, daily goal sheets). Especially close communication between staff nurses and physician leaders create an environment for good collaborative communication associated with positive patient, nurse, and physician outcomes [10,11], but also enhanced professional relationships, enhanced learning, increased nurse satisfaction, and decreased nurse job stress [12].

\section{Daily rounds}

Daily rounds are the basis to lay down the individual patient's diagnostic and therapeutic needs. Especially in the ICU, the problem of communication is essential as more or less the complete team (physicians as well as nurses) is generally changed three times a day. Moreover, there are several occurrences of information exchange when consultants from the treating specialties and other specialists visit their patients. This necessitates a strict and effective structure for rounds, ensuring the transfer of all necessary information, exchange of different positions and arguments, within a limited time schedule. Every instance of time wasted will frustrate all participants. On the other hand, it is mandatory that team members on duty get the necessary information to carry out their actual patient care. At the end, it must be sure who has to do what [13]. It is the leader's final responsibility to keep that delicate balance. An explicit approach that clearly appoints reporting and responsibilities during bedside rounds has been shown to improve considerably communication and the satisfaction of the staff [14]. 
Table 2

\begin{tabular}{ll}
\hline Rules for team briefings & \\
\hline Know the goals & ...be well prepared \\
Understand what & ...listen \\
Understand why & ...ask \\
Understand who & ...ask \\
Let the group discuss & ...but focused \\
Conclude & ...but briefly \\
& ....who has to do what? \\
\hline
\end{tabular}

\section{Team briefings}

Team briefings are a very valuable tool for communication of non-patient related problems. They provide direct information and reaction (upward communication), prevent misunderstandings, help people to accept changes and increase their commitment, and, last but not least, provide control and strengthen the leader's position. Rules for team briefings are listed in Table 2. Team briefings must take place on a regular basis and should not last too long; otherwise they become boring and create resistance. A high degree of discipline is mandatory to get the best out of such briefings. Again, it is the task of the leader to ensure the necessary balance between an open but focused discussion and a successful decision. The final message should be repeated in order to avoid misunderstandings $[8,9]$. Briefings can have a particular team-building quality.

\section{How to introduce beginners}

A specific area of communication is how to introduce beginners. The quite simple rule is 'the better you introduce beginners, the earlier they will be fit for their job'. Indeed quite simple, but so often neglected. A good introduction motivates people. Poorly motivated individuals generate most of the problems at the work place. Well organized, it starts with a period of introduction involving teaching and the providing of information, which is best controlled by individually nominated tutors. Thereafter, a period of accommodation begins, where individual communication and team briefing continue to build the connection. A regular evaluation (perceptible or not) makes clear what the individual's skills and experiences actually are and how he can be integrated into the daily work. This is a highly profitable procedure: the more the coworker feels he fits, the more he likes his job and the more he becomes an effective coworker [15]. It is the leader's responsibility to let the staff members stay at the ICU for a sufficient period of time; a frequent rate of staff exchange is counterproductive to any quality of care.

\section{Burnout}

The ICU is a very stressful environment, also for the personnel; therefore, a high incidence of burnout syndrome
(BOS) is obvious: about one-quarter of physicians in German ICUs were at risk for BOS [16]. A high degree of emotional exhaustion in internal ICU physicians derives from administration hassles, such as conflict resolution, bed-finding, and lack of support services [17]. One-third of French ICU nursing staff had severe BOS [18]. Problems significantly associated with BOS were (besides personal characteristcs) organizational factors (ability to choose days off), quality of working relations (conflicts with patients, relationship with head nurse/physicians), and end-of-life care. Interestingly, perceived burnout complaints among colleagues seemed to be an important factor in inducing BOS in other individuals of the staff [19]. ICU nurses' job satisfaction was strongly influenced by nurse-physician collaboration and nursing leadership behaviours [20]. This underlines the importance of creating and maintaining a good social atmosphere within the ICU team $[13,21,22]$.

\section{Conflict management}

Conflicts are defined as struggles between opposing forces. Although the word conflict generally has a negative connotation, this is not correct. Conflicts can be very useful for generating new ideas, stimulating creativity and bringing people closer together. An organization without conflicts is characterized by no changes and little motivation of the workers. An optimal amount of conflicts will generate creativity, a problem solving atmosphere, a strong team spirit, motivation and, as a result, changes. When conflicts become abundant, the organization will show a loss of energy, decreasing productivity, increasing stress and, finally, disintegration. Thus, we have to realize that conflicts can be useful, that they are inevitable when people work together but can also destroy an organization. An excess of conflicts is an indicator for failing leadership. Therefore, we need to understand the dynamics of conflicts and know how we can handle them in a way that they become fruitful $[23,24]$.

\section{Diagnostic path in conflicts}

Conflicts can be categorized into just four areas of emergence: task/organization, social/emotional, identity/vision and interests/goals/achievements. To understand a conflict, we have to know in which area the conflict has its roots, because the solution is linked to that area.

\section{Task/organization}

Such conflicts are caused by shortcomings in materials, methods, manpower, management and structure, thereby making it difficult for people to perform their tasks as they would like to or as they think they should do. Examples may be: malfunctioning computer system, pharmacy does not deliver in time, director is rigid or absent, not enough beds for planned production, restrictions of budget prohibiting optimal care. Possible interventions include development of procedures and guidelines, training of personnel, (re)structuring the organization, negotiating the budget and production targets. 


\section{Social/emotional}

These are problems of the interactions between individuals ('sympathy' and 'antipathy'). In working together you will find phrases like: "he is impossible to work with." Also, prejudice towards groups is located in this area: for example, "residents cannot be trusted with patients." Conflicts that find their roots in this area tend to carry a self-fulfilling prophecy: if you do not trust your residents, you will not give them responsibility. That means that you have to do everything on your own, reinforcing the feeling that residents are useless. Conflicts in this area are dangerous to your ward: they can poison the atmosphere and hamper productivity if not taken care of. Possible interventions include confrontation of people that hold these views and group training; if inevitable, discharge people.

\section{Identity/vision}

Here the question is: what is worthwhile to achieve as an ICU? Typically, a choice has to be made between two options that are mutually exclusive. Think of an open or closed format ICU; should it remain small (and beautiful) or grow its aspirations, choosing between quality or production? In these choices, which are fundamental for the existence of the unit, a compromise is impossible: it is either one or the other. The danger here is that someone 'loses' if an opposite direction is chosen. If this happens, there is a good chance that the conflict will transfer itself into the emotional area. Possible solutions include development of strategic goals, providing information, and intervening in culture.

\section{Interests/goals/achievements}

People have their individual goals, like having an adequate income, receiving training, doing research, taking career steps, teaching, and so on. Conflicts arise in this area when the goals or interests of individuals cannot be achieved. Because people can find it difficult to explicitly state their own interests, conflicts can erupt in one of the aforementioned areas. Be aware of this phenomenon and always ask yourself whether the source of a conflict might actually be found here. A possible solution involves negotiating.

\section{Conflicts with families or patients}

Conflicts with families or patients are a challenge that a well functioning ICU team must confidently be able to deal with [25]. In a group of ICU patients, exceeding the 85th percentile for length of stay, in almost a third of cases conflicts erupted [26]: of 248 conflicts identified in 209 patients from a cohort of 656 patients, the majority (142) were classified as family-team conflicts, usually about end of life decisions (44\%) or resulting from poor communication (44\%).

Taking end of life decisions as an example, and trying to place them in one of the four abovementioned conflict areas, it would seem that they would fit the identity/vision area. The choice between stopping treatment or continuation of treatment does not allow a compromise: it is either one or the other. Also here, listening is the key to finding a solution. Taking time to understand the position of the family can reveal that the source of the conflict may lie in feelings of guilt, being unable to decide upon such an important matter (area: interests/goals/achievements), no trust in the medical system or the attending doctor (area: social/emotional), or having the impression that scarcity of resources or improper procedures (area: task/organisation) strongly influence the choices that the doctors want to make. If any of this is the case, the proper intervention that can bring a solution has to be found in the specific conflict area.

In ICU teams that suffer from unresolved conflicts, a familyteam conflict can easily transform itself into an intra-team conflict. As professionals feel safe in medical matters, they are tempted to use a family-team conflict to bring in a conflict from another conflict area. Usually it concerns a conflict from the interests/goals/achievements area. The leader should be aware of this mechanism, recognise it, and approach it from an adequate angle to deal with it.

\section{Conflict phases}

Conflicts have their own dynamics. Typically, the problem starts as a 'latent conflict': opposing forces or ideas exist, but parties are still unaware of them. The next phase is characterized by becoming aware ('conflict emergence'): it becomes clear to both parties that opposing forces are present. Later, standpoints are firmly taken, and expressed ('conflict escalation'). At this stage, others also become aware that a conflict exists and are usually invited by the conflicting parties to take part in the conflict. If not solved in this phase, the conflict enters the 'hurting or stalemate phase': both parties do not move, make their standpoint as firm as possible and carry the burden of being involved in a conflict. Typically in this phase, parties damage each other and refuse to talk to each other. The fifth phase is called 'deescalation': parties have reached the insight that the hurting phase costs them too much and they become open to a possible settlement of the conflict. The tool for de-escalation is negotiation. Through that a 'dispute settlement' can be reached. Parties will agree upon a final solution to settle the argument. Last but not least (and often forgotten) is the 'postconflict peace building phase': both parties invest in normalization of their relationship. If peace building is not successfully accepted by both parties, the consequence will be a new conflict: remnants of an earlier conflict will be part of the new conflict with a quick escalation and a more profound hurting state.

\section{Conflict styles}

In dealing with a conflict, two variables are at stake: result and relationship. In an ideal situation, an excellent result can be achieved whilst at the same time the relationship with the other party improves. This is called integration, or a 'win-win' situation. An avoidant attitude towards conflicts will not lead to any result and also the relationship will not benefit. In this 
Figure 1

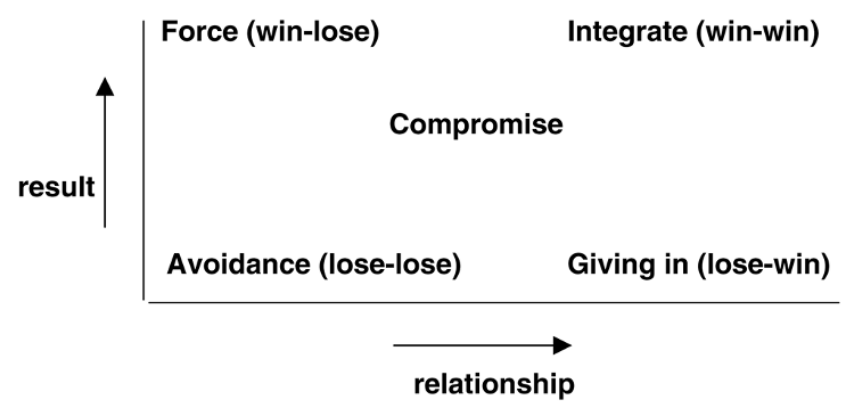

Conflict styles.

case, we speak of avoiding or 'lose-lose'. Somewhere midway between these extremes we find a compromise: you settle for some result, and you improve somewhat the relationship.

The other conflict style has either a result or the relationship as the ultimate goal: the result-driven ones go for the result and do not care if they lose the relationship. This style is adequate when you urgently need to admit a patient to your ward: you do not lengthily discuss the indication for admittance, thereby ignoring the feelings of your nurses. This style is known as the forcing style, or 'win-lose'. At the other extreme is the wish to keep the relationship at whatever cost. Here the style is giving in, or 'lose-win'; in this instance, a compromise may also be found midway between the two positions. The different styles are shown graphically in Figure 1.

From the above, it is clear that different conflicts require different conflict styles. Therefore, when dealing with a conflict one should decide on the value of the result and the value of the relationship. Only then an appropriate conflict style can be chosen. However, most people use the same conflict style for all conflicts. Adequate leadership requires the appropriate use of different conflict styles to obtain optimal results.

\section{Negotiations}

Conflicts are solved by negotiations. The negotiation phase has three main characteristics: the parties are dependent on each other (otherwise they do no have to negotiate); the parties have common as well as contradictory interests (the first is often forgotten, but is usually the key to a successful solution); and the parties aim at agreement.

Negotiating is primarily listening: try to understand what the real motives and goals of the other party are through asking questions. In this phase it is important to stress the common interests and then elucidate the area of conflict. Secondly, negotiating is making concessions. As it becomes clear what parties want, one should decide what the minimum is that is acceptable in a negotiated agreement. This minimum is referred to as 'BATNA', for 'best alternative to a negotiated agreement'. If the price for an agreement is too high, then an alternative to this agreement must be found. Before starting to make concessions the BATNA should be defined, otherwise the result might become too costly [24].

During the process of negotiation, the personal relationship should be taken care of. Negotiating is not fighting. Negotiators are not each other's enemies. Both parties aim at a good result and, if this cannot be reached, parties can get back to their alternatives for a negotiated agreement.

\section{Concessions}

At a certain point parties will have to make concessions to get through the negotiating process. For making concessions there are a few basic rules:

Make concessions late, make them smaller as time goes by. Concessions are precious in the process of negotiation, so do not throw them away. A common mistake is to give a concession early. In that case, the other party will accept it and thereafter start the real negotiation. Taking more time, and making concessions smaller as time goes by, is a clear signal to the other party that the point where nothing is to be given anymore has been reached.

Make concessions that do not cost you. What is valuable for one party might not be so important for the other party. In preparing for a negotiation try to understand what the other party wants. Identifying beforehand items that can easily be given away and offering them as concessions will keep the negotiation process going and force the other party to give something as well. Although these concessions do not cost much, in the course of negotiation they must be presented as precious concessions.

Always pair concessions. It is easy to give something away and the other party will be happy to take it. In order not to lose something without getting anything back, concessions should be paired. The usual form is: If I..., would you...?

Be explicit in saying what you want. With regard to this, a good preparation is again mandatory. If you are not explicit in saying what you want, the other party is given space for small concessions. In negotiating your budget, the question 'couldn't you do something more' will probably not result in a substantial rise. It is better to state the exact amount that you think is reasonable.

\section{Conclusion}

Management has become a profession itself. In the medical world, doctors are not trained to be managers. Still, many of us have managerial tasks. Literature on the management of the complex organisation that is the ICU is scarce. Management includes knowledge of leadership and of understanding 
and handling conflicts. In this article we have tried to provide some theoretical aspects, mostly derived from literature in non-medical fields, that we have recognised as useful for the medical profession. We hope that the information provided will bring better understanding and a possible starting point for improving skills, and further the development of organisation and communication.

\section{Competing interest}

The authors declare that they have no competing interests.

\section{References}

1. Shortell SM, Zimmerman JE, Rousseau DM, Gillies RR, Wagner DP, Draper EA, Knaus WA, Duffy J: The performance of intensive care units: does good management make a difference? Med Care 1994, 32:508-525.

2. Hersey $\mathrm{P}$, Blanchard $\mathrm{KH}$ : Management of Organizational Behavior: Utilizing Human Resources. Englewood Cliffs, NJ: PrenticeHall, Inc., 1977.

3. Kakabadse A, Bank J, Vinnicombe S: Working in Organisations. 2nd edition. Burlington, USA: Gower; 2004.

4. Covey SR: The Seven Habits of Highly Effective People. New York: Franklin Covey Co. Fireside; 1990.

5. Laporta DP, Burns J, Doig CJ: Bench-to-bedside review: dealing with increased intensive care unit staff turnover: a leadership challenge. Crit Care 2005, 9:454-458.

6. Roy K, Brunet $F$ : The role of leadership in overcoming staff turnover in critical care. Crit Care 2005, 9:422-423.

7. Goleman D: Emotional Intelligence. London: Bloomsbury; 1996.

8. Cowen J, Lindberg JM, Rainey TG: Proven strategies for keeping the team on track. Crit Connections, 2004, 3:number 6.

9. Cowen J, Lindberg J, Egol A, Rainey T: Tools for effective team communication. Crit Connections 2005, 4:number 1.

10. Boyle DK, Kochinda C: Enhancing collaborative communication of nurse and physician leadership in two intensive care units. J Nurs Adm 2004, 34:60-70.

11. Baggs JG, Schmitt MH, Mushlin Al, Mitchell PH, Eldredge $\mathrm{DH}$, Oakes D, Hutson AD: Association between nurse-physician collaboration and patient outcomes in three intensive care units. Crit Care Med 1999, 27:1991-1998.

12. Baggs JG, Schmitt MH, Mushlin Al, Eldredge DH, Oakes D, Hutson AD: Nurse-physician collaboration and satisfaction with the decision-making process in three critical care units. Am J Crit Care 1997, 6:393-399.

13. Pronovost $\mathrm{P}$, Berenholtz $\mathrm{S}$, Dorman T, Lipsett PA, Simmonds $T$, Haraden C: Improving communication in the ICU using daily goals. J Crit Care 2003, 18:71-75.

14. Dodek PM, Raboud J: Explicit approach to rounds in an ICU improves communication and satisfaction of providers. Intensive Care Med 2003, 29:1584-1588.

15. Mayberry JF: The management of poor performance. Postgrad Med J 2007, 83:105-108.

16. Kinzl JF, Traweger C, Biebl W, Lederer W: [Burnout and stress disorders in intensive care doctors]. Dtsch Med Wochenschr 2006, 131:2461-2464.

17. Guntupalli KK, Fromm RE: Burnout in the internist - intensivist. Intensive Care Med 1996, 22:625-630.

18. Poncet MC, Toullic P, Papazian L, Kentish-Barnes N, Timsit JF, Pochard F, Chevret S, Schlemmer B, Azoulay E: Burnout syndrome in critical care nursing staff. $A m J$ Respir Crit Care Med 2007, 175:698-704.

19. Bakker AB, Le Blanc PM, Schaufeli WB: Burnout contagion among intensive care nurses. $J$ Adv Nurs 2005, 51:276-287.

20. Bratt MM, Broome M, Kelber S, Lostocco L: Influence of stress and nursing leadership on job satisfaction of pediatric intensive care unit nurses. Am J Crit Care 2000, 9:307-317.

21. Duxbury ML, Armstrong GD, Drew DJ, Henly SJ: Head nurse leadership style with staff nurse burnout and job satisfaction in neonatal intensive care units. Nurs Res 1984, 33:97-101.

22. Vincent $P$, Billings $C$ : Unit management as a factor in stress among intensive care nursing personnel. Focus Crit Care 1988, 15:45-49.
23. Ritsema van Eck E, Huguenin P: Conflicthantering en onderhandelen. Houten: Bohn Stafleu Van Loghum; 1993.

24. Ury W: Getting Past No: Negotiating Your Way from Confrontation to Cooperation. Bantam Books Inc., 1993.

25. Kissoon N: Bench-to-bedside review: humanism in pediatric critical care medicine - a leadership challenge. Crit Care 2005 9:371-375.

26. Studdert DM, Mello MM, Burns JP, Puopolo AL, Galper BZ, Truog $\mathrm{RD}$, Brennan TA: Conflict in the care of patients with prolonged stay in the ICU: types, sources, and predictors. Intensive Care Med 2003, 29:1489-1497. 